\title{
The effects of nitric oxide cooling and the photodissociation of molecular oxygen on the thermosphere/ionosphere system over the Argentine Islands
}

\author{
G. D. Wells ${ }^{1}$, A. S. Rodger ${ }^{2}$, R. J. Moffett ${ }^{1}$, G. J. Bailey ${ }^{1}$, T. J. Fuller-Rowell ${ }^{3}$ \\ ${ }^{1}$ School of Mathematics and Statistics, The Hicks Building, University of Sheffield, Sheffield S3 7RH, UK \\ 2 British Antarctic Survey, Madingley Road, Cambridge CB3 0ET, UK \\ ${ }^{3}$ CIRES, University of Colorado/NOAA Space Environment Laboratory, 325 Broadway, Boulder, CO 80303, USA
}

Received: 20 March 1996 / Revised: 16 September 1996 / Accepted: 17 September 1996

\begin{abstract}
In the past the global, fully coupled, timedependent mathematical model of the Earth's thermosphere/ionosphere/plasmasphere (CTIP) has been unable to reproduce accurately observed values of the maximum plasma frequency, $f_{\mathrm{oF}}$, at extreme geophysical locations such as the Argentine Islands during the summer solstice where the ionosphere remains in sunlight throughout the day. This is probably because the seasonal dependence of thermospheric cooling by $5.3 \mu \mathrm{m}$ nitric oxide has been neglected and the photodissociation of $\mathrm{O}_{2}$ and heating rate calculations have been over-simplified. Now we have included an up-todate calculation of the solar EUV and UV thermospheric heating rate, coupled with a new calculation of a diurnally varying $\mathrm{O}_{2}$ photodissociation rate, in the model. Seasonally dependent $5.3 \mu \mathrm{m}$ nitric oxide cooling is also included. With these important improvements, it is found that model values of $f_{\mathrm{oF}} 2$ are in substantially better agreement with observation. The height of the F2-peak is reduced throughout the day, but remains within acceptable limits of values derived from observation, except at around $0600 \mathrm{~h} \mathrm{LT}$. We also carry out two studies of the sensitivity of the upper atmosphere to changes in the magnitude of nitric oxide cooling and photodissociation rates. We find that $\mathrm{hmF} 2$ increases with increased heating, whilst $f_{\mathrm{OF}} 2$ falls. The converse is true for an increase in the cooling rate. Similarly increasing the photodissociation rate increases both $\mathrm{hmF} 2$ and $f \mathrm{oF} 2$. These changes are explained in terms of changes in the neutral temperature, composition and neutral wind.
\end{abstract}

\section{Introduction}

The $\mathrm{O} / \mathrm{N}_{2}$ density ratio plays a crucial role in determining the magnitude and height of the peak electron density in the ionosphere, due to the sensitive nature of plasma production and loss mechanisms to changes in thermospheric composition. Atomic oxygen acts as a source of plasma. High $\mathrm{N}_{2}$ densities lead to an increased recombination rate, and hence an increase in the loss of plasma.

Heating of the thermosphere is a major factor in determining the $\mathrm{O} / \mathrm{N}_{2}$ density ratio. A high neutral temperature will result in a higher concentration of $\mathrm{N}_{2}$ (Burns et al., 1989) at a fixed altitude. Clearly, changes in the global circulation can lead to a lowering or raising of the $\mathrm{O} / \mathrm{N}_{2}$ ratio. Consequently, the corresponding electron concentration in the ionosphere will fall or rise. Similarly, a low neutral temperature results in higher concentrations of atomic oxygen, and a larger electron concentration. Therefore, it is crucial that we have a good understanding of the process involved in heating the thermosphere.

The main source of heat in the thermosphere is from solar EUV and UV radiation. For wavelengths $5 \mathrm{~nm}$ $<\lambda<135 \mathrm{~nm}$, the radiation is converted to heat via the photoionisation of the main thermospheric species. Above $130 \mathrm{~nm}$, the photodissociation of molecular oxygen is the main source of heat to the thermosphere.

This work was carried out using the Sheffield / UCL / SEL 3-dimensional, time-dependent, fully coupled thermosphere/ionosphere/plasmasphere (CTIP) model. The model, as previously described (Quegan et al., 1982; Fuller-Rowell et al., 1987; Fuller-Rowell et al., 1996; Millward et al., 1996), uses solar EUV and UV heating rates given by Creekmore et al. (1972). The rates are calculated using the flux values suggested in Hinteregger (1970) and Brinkman et al. (1966). For ease of computation, Creekmore et al. (1972) had to make certain assumptions about the heating process and the parameters involved. In this study, we present model results showing the thermospheric and ionospheric response to an up-to-date calculation of the solar heating rate, which includes recent solar fluxes and photoabsorption cross-sections. 
The photodissociation of molecular oxygen by solar radiation of wavelength $\lambda>135 \mathrm{~nm}$ provides the thermosphere with a source of atomic oxygen, as well as producing heating of the thermosphere. Previously, it was thought that a mean dissociation rate could be applied globally, as the large time constant (about $60 \mathrm{~h}$ at about $300 \mathrm{~km}$ ) meant that effects of a rate which varies with solar zenith angle could be ignored. At latitudes with 24 hour sunlight or 24 hour darkness, the long term effects of photodissociation will have a large effect on the upper atmosphere. We present model results showing the effect of a diurnally varying molecular oxygen dissociation rate, coupled with the new heating rates, on the thermosphere and ionosphere.

Heat can be lost from the thermosphere in several ways. The three important chemical heat loss processes are from atomic oxygen, nitric oxide and carbon dioxide cooling. Radiative cooling of the thermosphere by 63 $\mu \mathrm{m}$ atomic oxygen was previously included in CTIP as an explicit calculation (Fuller-Rowell et al., 1996). Global concentrations of nitric oxide are not calculated within CTIP, and consequently cooling by $5.3 \mu \mathrm{m} \mathrm{NO}$ has not been previously included as a part of the CTIP model. The concentration of NO, at a fixed altitude, increases by 3-4 times from winter to summer. There is a similar increase in the nitric oxide cooling rate (Richards et al., 1982). The $63 \mu \mathrm{m}$ cooling rate decreases by $30 \%$ due to the decrease in atomic oxygen density (Richards et al., 1982). Nitric oxide cooling is up to five times larger, at altitudes of $100-200 \mathrm{~km}$, than atomic oxygen cooling in the summer hemisphere. The inclusion of radiative heat loss from vibrationally excited nitric oxide will have a large effect on the upper atmosphere, especially in the summer hemisphere.

Solar EUV heating efficiency, the ratio of energy available to the thermosphere as heat to the total energy entering the thermosphere, is a term which has come under much scrutiny in the past by various workers (Chandra and Sinha, 1973; Stolarski et al., 1975; Torr et al., 1980a,b; Richards et al., 1982). Many methods of calculation have been adopted and different figures have been found. The peak solar EUV heating efficiency varies from 0.3 to 0.65 , and the altitude at which this occurs varies from $130 \mathrm{~km}$ to $190 \mathrm{~km}$. As defined, EUV heating efficiency does not include cooling processes but it is possible to perform calculations of an effective heating efficiency which include the effects of cooling processes.

Richards et al. (1982) performed calculations showing the effect of NO cooling on heating efficiency in the summer hemisphere. In this study we present model results showing the response and sensitivity of the upper atmosphere to the inclusion of nitric oxide cooling in the summer hemisphere. Richards et al. (1982) showed that the effects of NO cooling in the winter hemisphere are small, and therefore we do not include the effect in the winter.

Specifically, we will study the upper atmosphere over the Argentine Islands $\left(64^{\circ} \mathrm{S}, 65^{\circ} \mathrm{W}\right)$. Argentine Islands station has a high geographic latitude, but due to the offset of the geographic and geomagnetic poles, it is a geomagnetically mid-latitude station $(\mathrm{L}=2.3)$. This creates an extreme set of physical conditions, as Argentine Islands can exhibit certain high-latitude characteristics ( 24 hour daylight in summer), and certain mid-latitude characteristics (plasmaspheric refilling). This station thus provides us with a rigorous test of CTIP. The monthly median of ionosonde data for December 1978 of maximum plasma frequency, $f_{\mathrm{oF}}$, from Argentine Islands is shown in Fig. 1. The mean F10.7 solar flux for this month was 167 . The variation observed is mainly due to two factors: (1) 24 hour daylight at F-region altitudes means that there is a continuous source of photoionisation. Therefore, no rapid increase or decrease of plasma frequency normally associated with sunrise or sunset is observed. (2) Meridional winds, which blow equatorward between $1800-0600 \mathrm{~h} \mathrm{LT}$, force plasma upward along magnetic flux tubes, where the plasma has longer recombination time constant, so larger plasma frequencies than would otherwise be expected are observed. At local noon, the magnitude and position of the F2-layer is determined mainly by production and loss processes. Transport terms have little effect, so the strength and direction of the wind at this time is of little importance. These factors combined mean that the diurnal maximum in peak plasma frequency occurs at approximately $0300 \mathrm{~h}$ $\mathrm{LT}$, and has a value of $11 \mathrm{MHz}$. The minimum value of $7 \mathrm{MHz}$ occurs at $1300 \mathrm{~h} \mathrm{LT}$. The values of hmF2 are not directly available from the ionosonde data, and have to
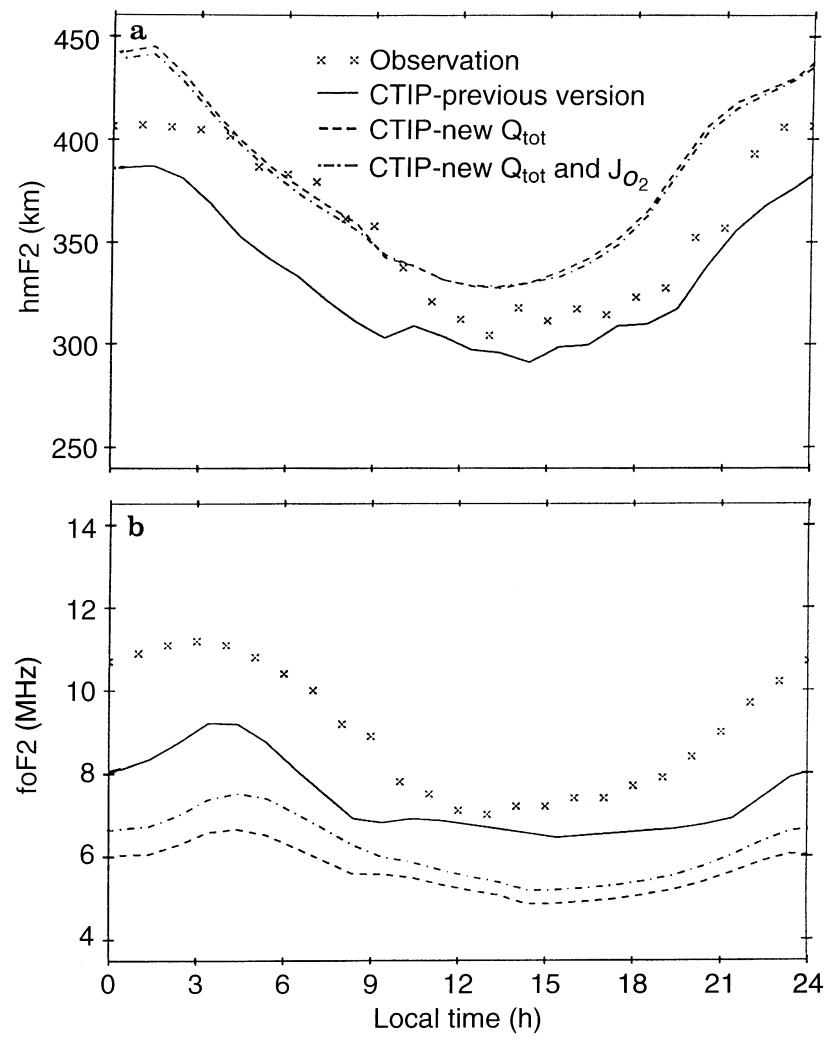

Fig. 1a,b. The effects of a new calculation of the solar heating and $\mathrm{O}_{2}$ photodissociation rate on $\mathbf{a} \mathrm{hmF} 2$ and $\mathbf{b} f \mathrm{oF} 2$ over Argentine Islands for December solstice conditions 
be deduced using formulae given by Dudeney (1983)(see Fig. 1a). A diurnal amplitude of approximately $100 \mathrm{~km}$ is observed and a maximum altitude of $400 \mathrm{~km}$ is achieved at local midnight. These characteristics are well understood and have been discussed by many authors (e.g. Dudeney and Piggott, 1978).

Neutral parameters (neutral temperature, mean molecular mass and neutral velocity) from CTIP are compared to parameters given by the MSIS 86 empirical thermospheric model (Hedin, 1987) and the HWM 90 horizontal wind model (Hedin et al., 1991). These models are best used in studies of climate change, but under quiet conditions they may be used to provide daily estimates of neutral parameters.

\section{Calculations}

The Sheffield/UCL global coupled model of the thermosphere/ionosphere/plasmasphere (CTIP) calculates the time-dependent global three-dimensional structure of the temperature, density, composition and vector velocity of the thermosphere, and the density, temperature and field-aligned velocity of the ions $\mathrm{O}^{+}$and $\mathrm{H}^{+}$, by solving nonlinear equations of continuity, momentum and energy.

\subsection{Solar EUV and UV heating in the thermosphere}

The solar EUV and UV heating rate in CTIP is calculated in two parts. For photons of wavelength $5 \mathrm{~nm}<\lambda<135 \mathrm{~nm}$, the primary mechanism for energy transfer to the neutrals is via photoionisation of the major species $\mathrm{O}, \mathrm{O}_{2}$ and $\mathrm{N}_{2}$. At a given altitude, $z$, the energy absorbed in these wavelengths, $Q_{e u v}(z)$, is given by

$$
\begin{aligned}
Q_{\text {euv }}(z)= & \int_{\lambda<135 n m} \sum_{i} n_{i}(z) \sigma_{i}(\lambda) \phi_{\infty}(\lambda) . \\
& \exp \left(-\sum_{i} \tau_{i}(\lambda, z)\right) d \lambda
\end{aligned}
$$

where

$n_{i}(z)=$ concentration of $\mathrm{i}^{\text {th }}$ absorber at height $z \mathrm{~km}$
$\left(\mathrm{~m}^{-3}\right)$
$\sigma_{i}(\lambda)=$ photoabsorption cross-section of species $i$, at wavelength $\lambda\left(\mathrm{m}^{2}\right)$

$\phi_{\infty}(\lambda)=$ unattenuated solar energy flux of wavelength $\lambda\left(\mathrm{J} \mathrm{m}^{-2} \mathrm{~s}^{-1}\right)$

$\tau_{i}(\lambda, z)=$ optical depth of species $i$ at altitude $z$ and wavelength $\lambda$.

Photoabsorption cross-sections for this wavelength range are taken from Torr and Torr (1982). The solar flux values are taken from Tobiska (1991).

For photons with wavelength $\lambda>135 \mathrm{~nm}$, the initial mechanism for heat transfer to the neutral gas is via the photodissociation of molecular oxygen. The energy absorbed at an altitude $z \mathrm{~km}$ in these wavelengths, $Q_{u v}(z)$, is given by

$Q_{u v}(z)=\int_{\lambda>135 n m} n_{O_{2}}(z) \sigma_{O_{2}}(\lambda) \phi_{\infty}(\lambda) \exp \left(-\tau_{O_{2}}(\lambda, z)\right) d \lambda$

In this case, the only species contributing is molecular oxygen. The photoabsorption cross-sections and the solar fluxes used are given in Table 1. The fluxes shown correspond to an F10.7 index of 70. For the purposes of this study, the fluxes have been scaled to an F10.7 index of 165 by using the formula

$\phi_{165}=\phi_{70} \times \frac{165}{70}$

Table 1. Unattenuated solar flux intensities and photoabsorption cross-sections for wavelengths 135-195 nm. Solar flux intensities are taken from Heroux and Hinteregger (1978) and correspond to an F10.7 of 70 . For wavelengths $\lambda<175 \mathrm{~nm}$ photoabsorption cross-sections are taken from Torr et al. (1980b); all other cross-sections are taken from Watanabe (1958)

\begin{tabular}{lccc}
\hline $\begin{array}{l}\text { Wavelength } \\
\text { Interval } \\
(\mathrm{nm})\end{array}$ & $\begin{array}{l}\text { Solar flux } \\
\mathrm{F}_{\infty} \\
\left(\times 10^{13} \text { photons } \mathrm{m}^{-2} \mathrm{~s}^{-1}\right)\end{array}$ & $\begin{array}{l}\text { Solar flux } \\
\phi_{\infty} \\
\left(\times 10^{-6} \mathrm{~J} \mathrm{~m}^{-2} \mathrm{~s}^{-1}\right)\end{array}$ & $\begin{array}{l}\text { Photobsorption } \\
\text { cross-section } \sigma_{a b s} \\
\left(\times 10^{-23} \mathrm{~m}^{2}\right)\end{array}$ \\
\hline $135-140$ & 8.7 & 126 & 120.0 \\
$140-145$ & 11.3 & 158 & 150.0 \\
$145-150$ & 16.2 & 218 & 130.0 \\
$150-155$ & 29.0 & 430 & 100.0 \\
$155-160$ & 44.4 & 560 & 60.0 \\
$160-165$ & 56.0 & 680 & 34.0 \\
$165-170$ & 138.5 & 1652 & 15.0 \\
$170-175$ & 225.0 & 2590 & 5.0 \\
$175-180$ & 357.0 & 3990 & 1.0 \\
$180-185$ & 632.9 & 6826 & 0.2 \\
$185-190$ & 777.0 & 8230 & 0.4 \\
$190-195$ & 829.0 & 8580 & 0.01 \\
\hline
\end{tabular}


Here $\phi_{70}$ corresponds to flux values using an F10.7 of 70. The dependence of solar flux on solar activity in the wavelength region 135-195 $\mathrm{nm}$ steadily weakens with increasing wavelength. Consequently, Eq. (3) will overestimate the solar flux in this region. However, the uncertainties associated with parameters such as solar flux and photoabsorption cross-sections implies that a high degree of accuracy is difficult to obtain. Having calculated the energy absorbed as a result of the two major processes, it is possible to calculate the total energy converted to heat

$\mathrm{Q}_{\text {tot }}=\eta_{\text {tot }}\left(\mathrm{Q}_{\text {ewv }}+\mathrm{Q}_{u v}\right)$

where

$\eta_{t o t}=$ overall neutral heating efficiency

\subsection{Nitric oxide cooling}

We utilise the results of Richards et al. (1982) who performed calculations of an effective heating efficiency, which included the effects of $5.3 \mu \mathrm{m}$ NO cooling and $63 \mu \mathrm{m}$ atomic oxygen cooling, both individually and together. Their results are shown in Fig. 2. The inclusion of $5.3 \mu \mathrm{m}$ NO cooling in the summer hemisphere results in a reduction in peak heating efficiency from 0.6 to 0.45 . The height of the peak increases from $170 \mathrm{~km}$ to $190 \mathrm{~km}$. We have adopted this new profile for heating efficiency in the summer hemisphere only. The effects of cooling by $63 \mu \mathrm{m}$ atomic oxygen need not be included as a part of the heating efficiency calculation, as they are calculated explicitly in CTIP.

Richards et al. (1982) do not suggest possible limits for the profile of $\eta$. It is important to assess the uncertainty of the magnitude of the heating efficiency. The range of the peak heating efficiency quoted by various authors in $0.3-0.6$. These limits are approximately $\pm 25 \%$ either side of the 0.45 peak efficiency

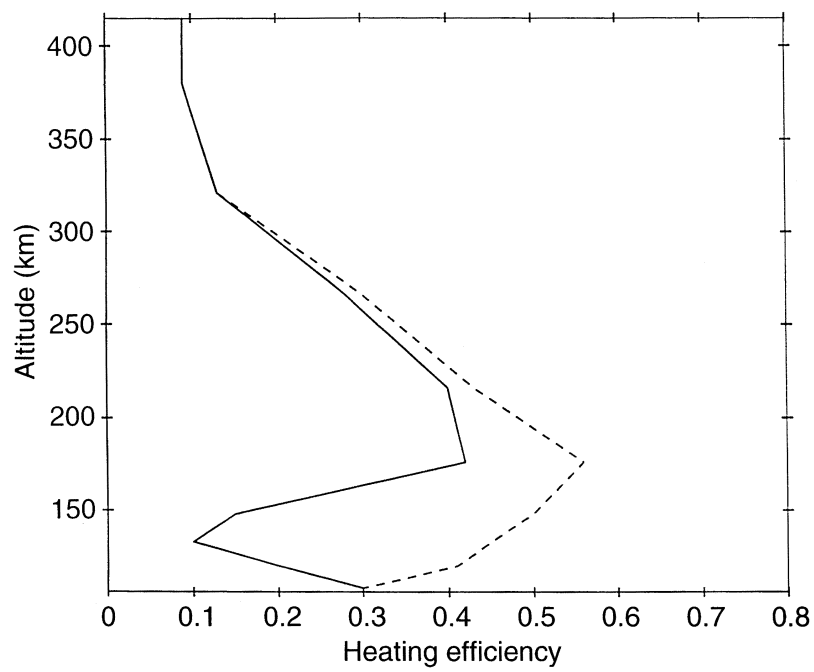

Fig. 2. Without NO cooling (solid) and with NO cooling (dashed) altitude profiles of heating efficiency used in CTIP which we have used. Thus we have chosen to simply multiply the heating efficiency profile throughout by $\pm 25 \%$ and use the resulting profiles as our limits for the uncertainty of the original.

\subsection{Diurnally varying dissociation rate}

The reaction

$\mathrm{O}_{2}+\mathrm{h} v \rightarrow \mathrm{O}+\mathrm{O}$

is an important source of atomic oxygen, as well as being a source of heat in the thermosphere. The reaction rate for this reaction is given by

$\mathrm{J}_{O_{2}}=\int_{\lambda>135 n m} F_{\infty}(\lambda) \sigma_{O_{2}} \exp \left(-\tau_{O_{2}}(\lambda, z)\right) d \lambda$

This is essentially the same calculation as Eq. (2), except that the flux used, $F_{\infty}$, is measured in photons $\mathrm{m}^{-2} \mathrm{~s}^{-1}$, as opposed to $\phi_{\infty}$, measured in $\mathrm{J} \mathrm{m}^{-2} \mathrm{~s}^{-1}$. The volume production rate for atomic oxygen is simply $2 \times \mathrm{J}_{\mathrm{O}_{2}}$. The rate previously used in CTIP was simply a diurnally constant globally averaged figure described by Fuller-Rowell and Rees (1980), which was only dependent on F10.7. It was thought that the large time constant associated with the process (Burns et al., 1989) meant that the rate need not vary with solar zenith angle. However, in regions with 24 hour sunlight or 24 hour darkness a globally constant dissociation rate will not adequately describe the physics of the process. It is important to assess the effect that a diurnally varying dissociation rate will have on the physics of the thermosphere, with particular emphasis on regions with constant darkness/sunlight.

Many of the solar fluxes and photoabsorption crosssections are subject to a large amount of uncertainty, with respect to their magnitude. Therefore it was decided to investigate the sensitivity of the thermosphere/ionosphere to changes in $\mathrm{J}_{\mathrm{O}_{2}}$. The values chosen for the extremes in this investigation were $\mathrm{J}_{\mathrm{O}_{2}} \times 2.0$ and $\mathrm{J}_{\mathrm{O}_{2}} \times 0.5$. This provides us with a range of results adequate to assess the full effects of $\mathrm{J}_{\mathrm{O}_{2}}$.

\section{Results and discussion}

Initial conditions for subsequent runs were provided by the output from a standard coupled model run, under conditions of December solstice, F10.7=165 and Tiros precipitation level $5\left(K_{p} \simeq 2^{+}\right)$. The model was run until a diurnally steady state was achieved. The results of this run can be seen in Figs. 1 and 3 (solid lines). As the thermosphere is the major determinant of the magnitude and variation of parameters in the ionosphere, results from the thermosphere will be discussed before those of the ionosphere.

A plot of neutral temperature, $T_{n}$, from CTIP versus local time over Argentine Islands at $300 \mathrm{~km}$ altitude for the December solstice can be seen in Fig. 3a. Also shown is the corresponding curve for the MSIS 86 empirical thermosphere model. The maximum temperature of 

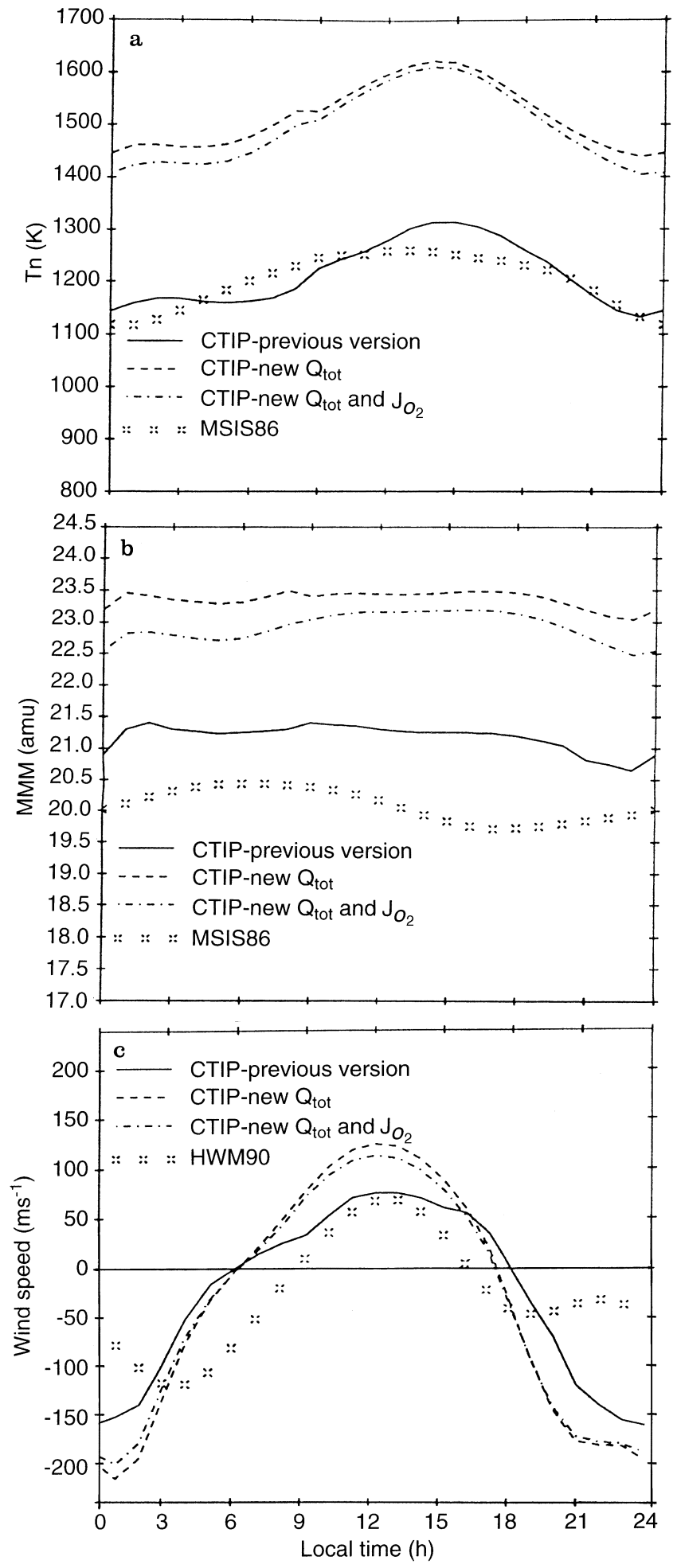

Fig. 3a-c. The effects of a new calculation of the solar heating and $\mathrm{O}_{2}$ photodissociation rate on $\mathbf{a} T_{n} ; \mathbf{b} \mathrm{mmm}$ and $\mathbf{c} V_{x}$ (positive polewards) over Argentine Islands at $300 \mathrm{~km}$, for December solstice conditions. The solid line refers to CTIP before any changes had been implemented

$1300 \mathrm{~K}$ given by CTIP is $50 \mathrm{~K}$ larger than that suggested by MSIS 86. The maximum in CTIP occurs at $1500 \mathrm{~h}$ LT, whereas MSIS 86 puts the maximum value of $T_{n}$ at $1300 \mathrm{~h} \mathrm{LT}$. The minima of the two temperature distributions are approximately concurrent around local midnight. Both models give a minimum value of about $1120 \mathrm{~K}$. Here, we refer to old CTIP results (solid curve), meaning CTIP as it stood before any changes were implemented.

Figure $3 \mathrm{~b}$ shows the diurnal variation of the mean molecular mass $(\mathrm{mmm})$ at $300 \mathrm{~km}$ for both models over Argentine Islands. The CTIP model results are larger than the MSIS 86 results by at least $0.75 \mathrm{amu}$ throughout the $24 \mathrm{~h}$ period. Consequently, the $\mathrm{O} / \mathrm{N}_{2}$ ratio of CTIP is lower than that of the MSIS 86 model. The largest differences occur between 1200-2100 h LT, and at $1700 \mathrm{~h} \mathrm{LT}$ the difference reaches $1.5 \mathrm{amu}$. A maximum value of $20.4 \mathrm{amu}$ is seen at $0600 \mathrm{~h} \mathrm{LT}$ for the MSIS 86 curve, whereas the CTIP model suggests a maximum of $21.4 \mathrm{amu}$ at about $0200 \mathrm{~h} \mathrm{LT}$. The minimum value of $\mathrm{mmm}$ given by the CTIP model is concurrent with the minimum of $T_{n}$ at around $0000 \mathrm{~h}$ LT. MSIS 86 places the minimum in $\mathrm{mmm}$, when the thermosphere has the largest concentration of atomic oxygen at a fixed height, at $1700 \mathrm{~h} \mathrm{LT}$. Again, we refer to old CTIP results only.

As described earlier, the meridional component of the neutral wind, $V_{x}$ (positive in the polewards direction), plays an important role in determining the shape and magnitude of the F2-layer. A large equatorward value of $V_{x}$ around local midnight causes the increases in $f \mathrm{oF} 2$ and $\mathrm{hmF} 2$ observed. Figure $3 \mathrm{c}$ shows the value of $V_{x}$ at $300 \mathrm{~km}$ throughout a 24 hour period. Also shown for comparison is the value of $V_{x}$ under similar conditions, taken from the HWM 90 horizontal wind model. A maximum equatorward value of $140 \mathrm{~ms}^{-1}$ from CTIP, at local midnight, is seen.

Figure 1a shows the diurnal variation of $\mathrm{hmF} 2$ over Argentine Islands for old CTIP (solid curve) in comparison to values derived from observation. The diurnal amplitude of the model results is about $100 \mathrm{~km}$, which is similar to the observations. This implies that the neutral wind in CTIP is of sufficient magnitude to produce the required variation in the height of the F2layer. However, the model results are consistently lower in altitude than the derived values, by up to $50 \mathrm{~km}$ at around $0700 \mathrm{~h} \mathrm{LT}$. Between 1000-2100 h LT the two curves only differ by $10 \mathrm{~km}$. The phases of the two curves are similar. Due to the large vertical resolution of CTIP, and the errors that such a scale can cause, a value within one half a scale height of the neutral gas of the observation can be considered a reasonable one. The scale height of the neutral gas at an altitude of $380 \mathrm{~km}$ is about $50 \mathrm{~km}$. Therefore, a modelled value within $20 \mathrm{~km}$ of the observation is reasonable. The values of $\mathrm{hmF} 2$ derived from observation are also subject to an uncertainty, and should only be considered accurate to within $20 \mathrm{~km}$.

The large concentration of $\mathrm{N}_{2}$ which occurs in CTIP in summer, which in this case also occurs on fixed pressure levels, leads to an F2 layer which has a much lower plasma frequency than is seen over Argentine Islands (Fig. 1b). CTIP gives an $f_{\mathrm{O}} \mathrm{F} 2$ curve which is lower in magnitude and flatter than observation. The diurnal amplitude of the maximum plasma frequency 
given by CTIP is $1.5 \mathrm{MHz}$ smaller than the observed diurnal variation. A maximum observed value of 11 $\mathrm{MHz}$, occurring at $0300 \mathrm{LT}$, is $1.5 \mathrm{MHz}$ higher than the corresponding maximum given in CTIP. The two curves have similar phases.

\subsection{Effects of new heating rate and dissociation rate}

Figure 4 shows altitude profiles at local noon and local midnight over Argentine Islands of the heating rates given by Creekmore et al. (1972) and the up-to-date calculation described earlier. The profiles represent heating rates after multiplication by heating efficiency. Below $250 \mathrm{~km}$ both old and new rates are one order of magnitude larger at local noon than at local midnight. In the range of $100-350 \mathrm{~km}$ altitude, the region where the largest amount of thermospheric heating occurs, the new rates are consistently higher than the Creekmore et al. (1972) rates. In this region at local midnight the new rates are up to 2.5 times larger than the rates suggested by Creekmore et al. (1972).

As a result of larger heating rates in the region $100-550 \mathrm{~km}$, an increase of $250 \mathrm{~K}$ occurs in the model $T_{n}$ at $300 \mathrm{~km}$ (Fig. 3a, dotted line). The diurnal amplitude and phase of $T_{n}$ remain similiar. A high value for the neutral temperature and, in this case, consequent change in the global circulation, will imply a large percentage of molecular species in the thermosphere at a given height (Burns et al., 1989) and on a fixed pressure level. Figure $3 \mathrm{~b}$ (dotted line) gives a comparison of the molecular mass associated with both sets of heating rates at $300 \mathrm{~km}$. When the new, larger, heating rates are used an increase of $2 \mathrm{amu}$ is seen throughout the day. The maximum value of $23.5 \mathrm{amu}$ is $3 \mathrm{amu}$ higher than the value suggested by MSIS 86 . The new heating rate has had little effect on the diurnal phase of the composition of the thermosphere.

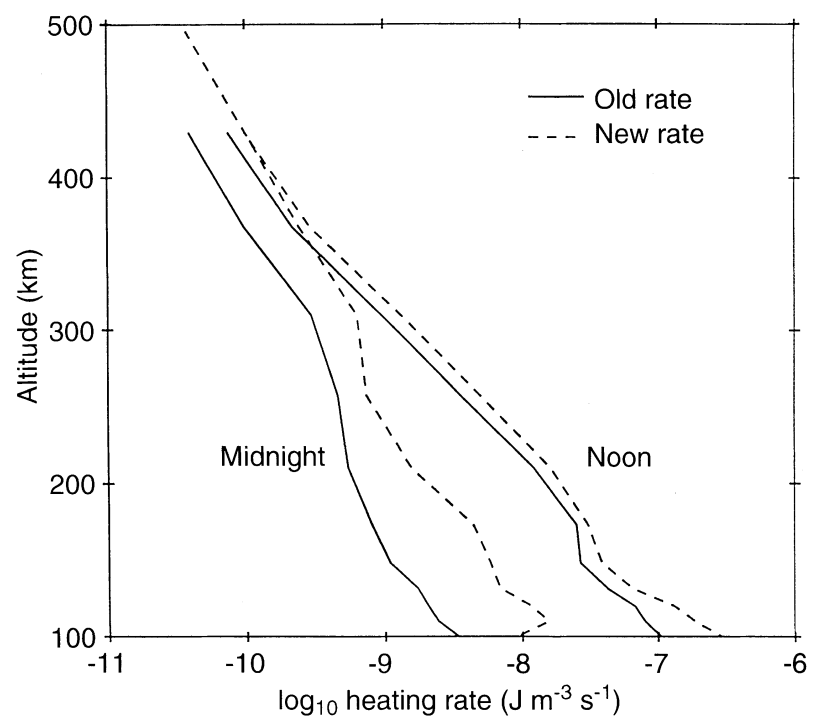

Fig. 4. Altitude profiles of solar heating rates for local noon and local midnight over Argentine Islands. Shown are the rates of Creekmore et al. (1972) and the revised rates, at December solstice
The new heating rate has caused an increase in the magnitude of the meridional component of the neutral wind (Fig. 3c, dotted line). The largest poleward and equatorward winds are $120 \mathrm{~ms}^{-1}$ and $200 \mathrm{~ms}^{-1}$ respectively. This wind is sufficient to produce a diurnal amplitude of $100 \mathrm{~km}$ in hmF2 (Fig. 1a, dotted line). The larger rates have caused the thermosphere to thermally expand, and this has the effect of raising the level at which the F2-layer forms by $50 \mathrm{~km}$. A better agreement with the derived values, at most local times, has been achieved.

The increase in $N_{2}$ concentration caused by the new rates and the subsequent increase in plasma recombination loss rates have meant that $f_{\mathrm{OF}} 2$ has fallen. The maximum $f_{\mathrm{OF}} 2$ occurs at the same time as previously, but is now $6.6 \mathrm{MHz}$, over $4 \mathrm{MHz}$ below the observed maximum (Fig. 1b, dotted line). $f_{\mathrm{oF}} 2$ is flatter than previously with a diurnal amplitude of about $1.7 \mathrm{MHz}$, compared with the observed diurnal amplitude of 4 $\mathrm{MHz}$. The new rates have the smallest effect on $f_{\mathrm{oF}} 2$ between 0800-2000 h LT.

Altitude profiles of the diurnally varying dissociation rate over Argentine Islands at local noon and local midnight are shown in comparison with the previously constant rate in Fig. 5. The photodissociation of molecular oxygen becomes significant in the region below $200 \mathrm{~km}$. In this region, the dissociation rate at local noon over Argentine Islands during December solstice is consistently greater, by up to a factor of two, than the old rate. However, the old rate is up to a factor of two larger than the diurnally-varying rate at local midnight. Above $200 \mathrm{~km}$ the concentration of $\mathrm{O}_{2}$ is sufficiently small for the process to be almost negligible.

The effects of adding a diurnally-varying dissociation rate in addition to the new heating rate, can be seen in Figs. 1 and 3 (dot-dashed lines). The process has a small effect on the neutral temperature (Fig. 3a), but it is unlikely that this effect is of any significance to the

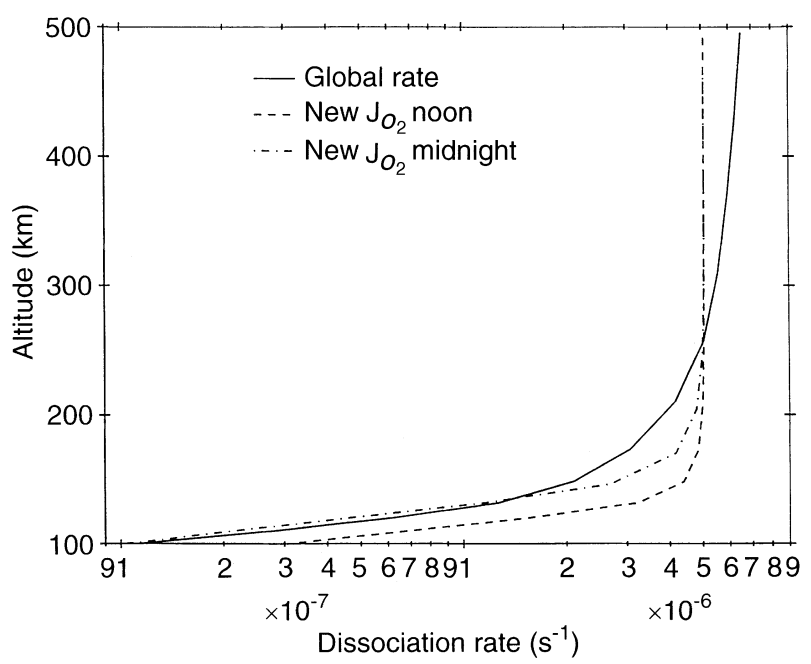

Fig. 5. Altitude profiles of the $\mathrm{O}_{2}$ photodissociation rate over Argentine Islands for local noon and local midnight, at December solstice 
thermosphere. The most significant effect of the addition of the new rate is seen in Fig. 3b. A decrease of $0.5 \mathrm{amu}$ is seen in mmm at $300 \mathrm{~km}$, throughout the day. This is due to the extra source of atomic oxygen that the increased rate provides. Consequently the $\mathrm{O} / \mathrm{N}_{2}$ ratio on fixed pressure levels throughout the thermosphere increases. The effect of the inclusion of the new dissociation rate on the meridional component of the neutral wind is negligible (Fig. 3c).

The results of a diurnally varying dissociation rate in the ionosphere are shown in Fig. 1a-b. The small change in neutral temperature and wind strength have meant that $\mathrm{hmF} 2$ remains unaltered by the change (Fig. 1a). The slight increase in the $\mathrm{O} / \mathrm{N}_{2}$ ratio, however, leads to an overall increase in the values of $f_{\mathrm{O}} \mathrm{F} 2$ (Fig. 1b). The maximum value increases by about $0.7 \mathrm{MHz}$ to slightly below $8 \mathrm{MHz}$. The new dissociation rates have the smallest effect on $f_{\mathrm{OF}} 2$ between $0800-2000 \mathrm{~h} \mathrm{LT}$. The values of $f_{\mathrm{OF}} 2$ obtained are approximately $1 \mathrm{MHz}$ below the values obtained when the Creekmore et al. (1972) heating rates and a globally constant dissociation rate were used.

\subsection{Effects of NO cooling}

The physical consequences of the inclusion of $5.3 \mu \mathrm{m}$ NO cooling as a part of the heating efficiency calculation can be seen in Figs. 6 and 7. Also shown, as a comparison, are the CTIP model runs which were performed using the new heating and dissociation rates.

The immediate effect of introducing an extra cooling term is to reduce the neutral temperature. Figure 6a shows that the model $T_{n}$ is now always within $50 \mathrm{~K}$ of the MSIS 86 values. The main discrepancy between the two curves occurs between 0300-0900 h LT. The temperature given by MSIS 86 increases during this period, while the CTIP model temperatures are seen to decrease. The extra cooling does not effect the phase or diurnal amplitude of $T_{n}$.

The effects on thermospheric composition of $5.3 \mu \mathrm{m}$ NO cooling are shown in Fig. 6b. A reduction of about $2 \mathrm{amu}$ in $\mathrm{mmm}$ at $300 \mathrm{~km}$ has occurred and, consequently, CTIP and MSIS 86 have a much improved agreement and now are within about $0.5 \mathrm{amu}$ at all times.

The magnitude of $V_{x}$ is reduced by the extra heat loss from the thermosphere, but at local midnight, the equatorward wind remains above $100 \mathrm{~ms}^{-1}$ (Fig. 6c). This value is adequate to produce the required diurnal variation in hmF2 (Fig. 7a). The thermosphere has cooled and hence contracted. The height of the F2-peak over Argentine Islands has fallen by $50 \mathrm{~km}$ throughout the day, to a value similar to the previous CTIP result (see Fig. 1a)

The agreement in $f_{\mathrm{OF}} 2$ between CTIP and observation over Argentine Islands is very much improved after the inclusion of NO cooling in the summer hemisphere (Fig. 7b). The two curves now have the same concurrent maximum value of $11 \mathrm{MHz}$. The diurnal amplitude of $f_{\mathrm{OF}} 2$ has increased to $4 \mathrm{MHz}$, and is now comparable to observation.
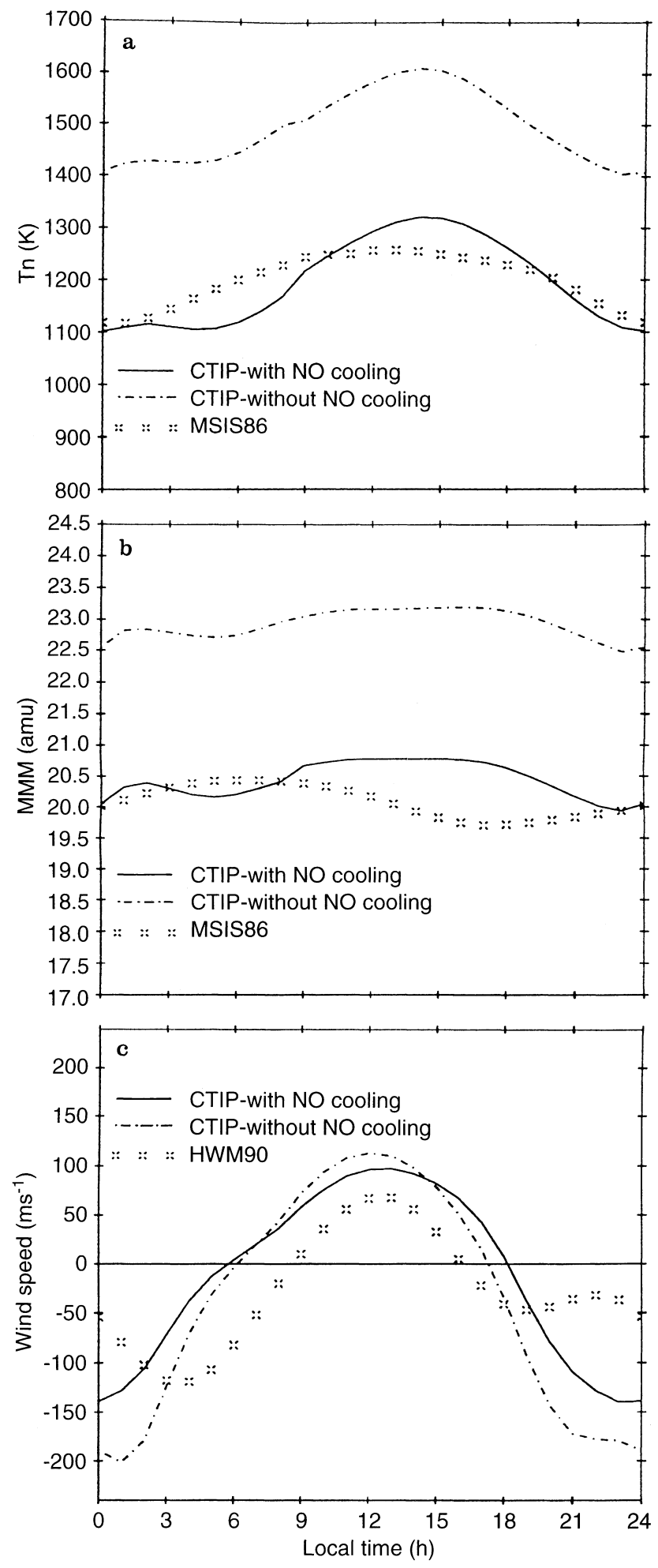

Fig. 6a-c. The effect of NO cooling on the neutral parameters a $T_{n} ; \mathbf{b}$ mmm and $\mathbf{c} V_{x}$ (positive polewards) at $300 \mathrm{~km}$ over Argentine Islands (with new heating rate and photodissociation already included in CTIP)

\section{Sensitivity to heating efficiency}

The effects on the thermosphere and ionosphere over Argentine Islands of increasing/decreasing the values of 

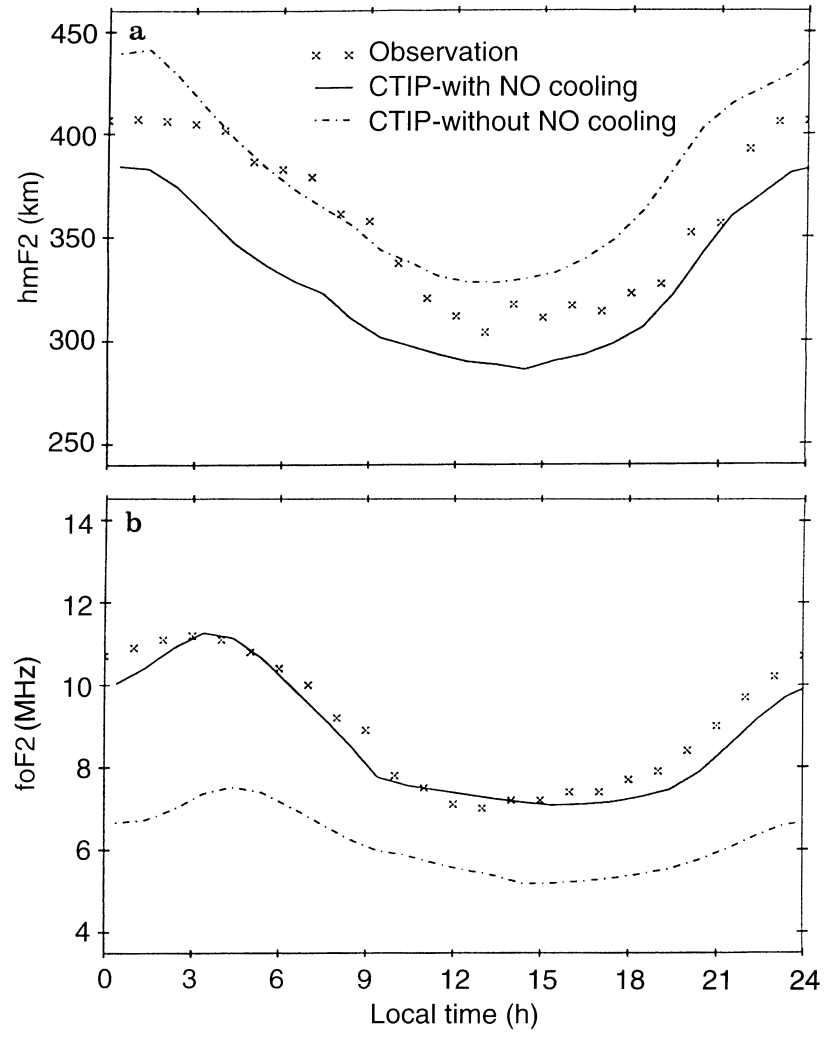

Fig. 7a,b. The effect of $\mathrm{NO}$ cooling on $\mathbf{a} \mathrm{hmF} 2$ and $\mathbf{b} f_{\mathrm{oF}} 2$ over Argentine Islands

summer heating efficiency (as suggested by Richards et al., 1982) by $25 \%$ can be seen in Figs. 8 and 9 . The neutral temperature over Argentine Islands at $300 \mathrm{~km}$ is shown in Fig. 8a. The changes of the neutral heating efficiency and the neutral temperature are almost linearly related at this altitude. A change in the heating efficiency of the thermosphere does not effect the phase of $T_{n}$.

The mean molecular mass at $300 \mathrm{~km}$ responds as one might expect to changes in the amount of heating of the thermosphere and in the global circulation. The increase in $T_{n}$ is followed by an increase in the concentration of $\mathrm{N}_{2}$ at $300 \mathrm{~km}$. This is reflected in Fig. $8 \mathrm{~b}$ by an increase of approximately $2 \mathrm{amu}$ in the $\mathrm{mmm}$ at $300 \mathrm{~km}$ over Argentine Islands. A lowering of neutral heating efficiency $\left(\eta_{t o t}\right)$, i.e. an increase in the magnitude of NO cooling, results in a thermosphere with a greater concentration of atomic oxygen. The $\mathrm{mmm}$ at $300 \mathrm{~km}$ has decreased by approximately 2 amu. Again, the changes in heating efficiency and thermospheric composition are almost linearly related at this altitude, and the phase of the mmm remains unaffected.

The sensitivity of the meridional component of the neutral wind over Argentine Islands to a change in thermospheric heating is shown in Fig. 8c. Increasing $\eta_{\text {tot }}$ by $25 \%$ leads to an increase of approximately $20 \mathrm{~m} \mathrm{~s}^{-1}$ in the maximum equatorward value of $V_{x}$. The period of time for which the wind is in the equatorward direction has increased from 12 to $13 \mathrm{~h}$. Similarly, a decrease of $25 \%$ in $\eta_{t o t}$ leads to a decrease of approxi-
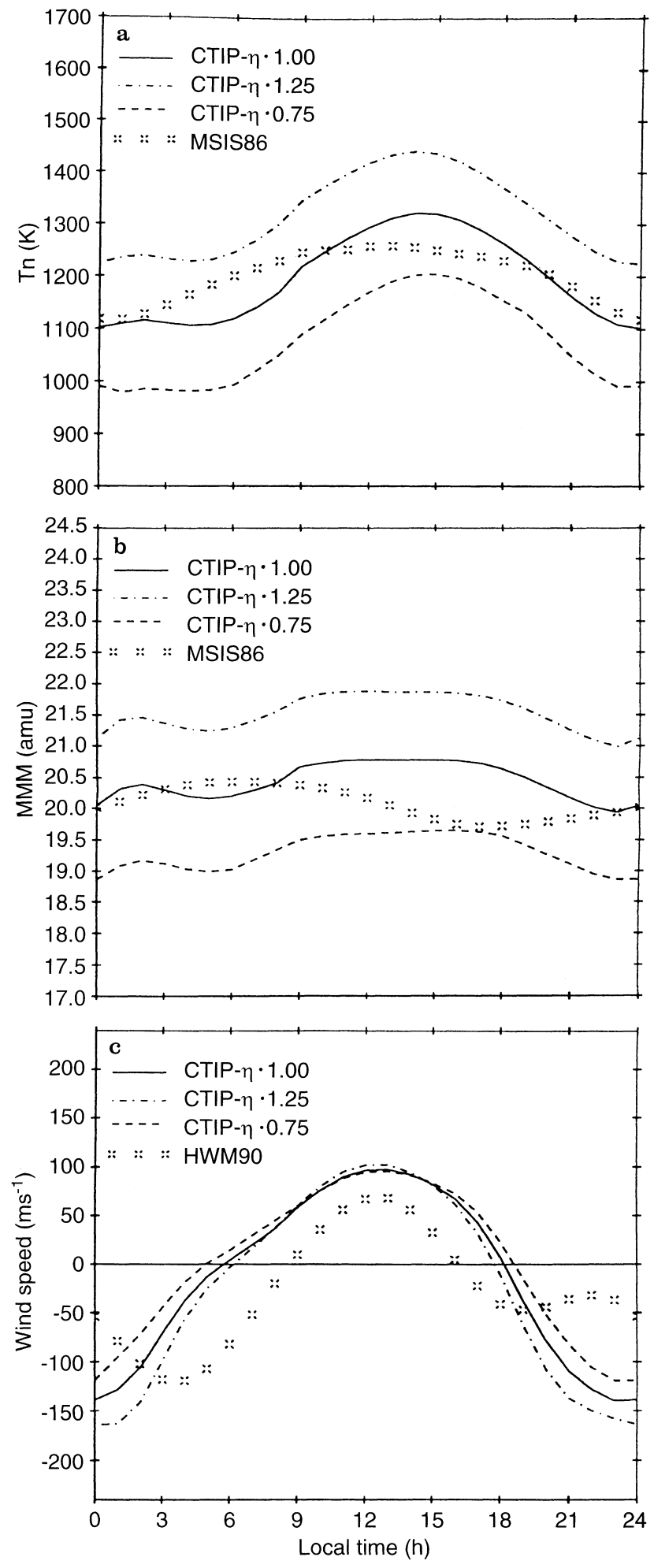

Fig. 8a-c. The sensitivity of a $T_{n}, \mathbf{b} \mathrm{mmm}$ and $\mathbf{c} V_{x}$ (positive polewards), at $300 \mathrm{~km}$ over Argentine Islands, to changes in the magnitude of thermospheric heating efficiency

mately $20 \mathrm{~m} \mathrm{~s}^{-1}$ in the magnitude of $V_{x}$ around local midnight. The length of time that $V_{x}$ is in the equatorward direction has reduced to only 11 hours.

The changes that have occurred in the thermosphere have important effects in the ionosphere, especially at 

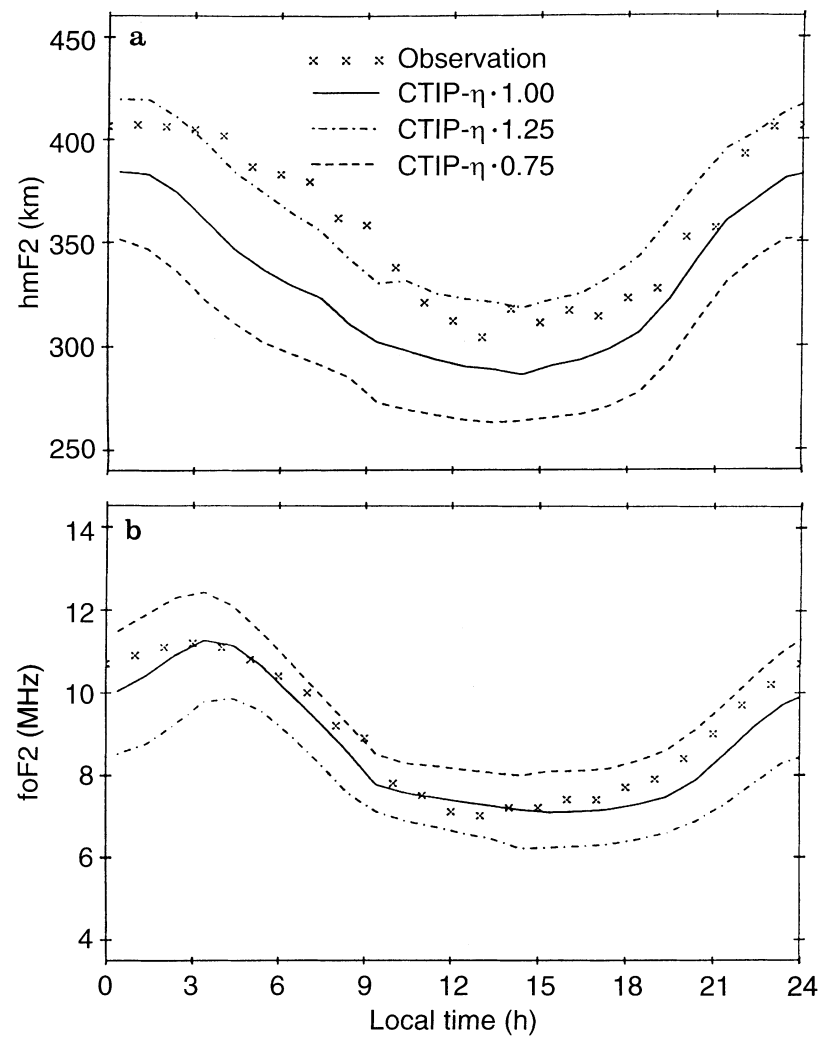

Fig. 9a,b. The sensitivity of a hmF2 and b foF2, over Argentine Islands, to changes in the magnitude of thermospheric heating efficiency

F-region altitudes. However, whereas the effect of a $\pm 25 \%$ change in the magnitude of the heating efficiency leads to approximately linear changes in the neutral parameters $T_{n}, \mathrm{mmm}$ and $V_{x}$, ionospheric parameters are altered in a more complicated way. Figure $9 \mathrm{a}-\mathrm{b}$ shows the sensitivity of the diurnal variation of $\mathrm{hmF} 2$ and $f_{\mathrm{OF}} 2$ to the alterations in heating efficiency. The thermal expansion of the thermosphere caused by the largest value of $\eta_{\text {tot }}$ has raised $\mathrm{hmF} 2$ by $30 \mathrm{~km}$. The new values are in good agreement with the values derived from observation (Fig. 9a). However, Fig. 9b shows that $f_{\mathrm{oF}} 2$ falls as a result of the increased concentration of $\mathrm{N}_{2}$. The maximum $f \mathrm{oF} 2$ over Argentine Islands corresponding to large $\eta_{\text {tot }}$ is $10 \mathrm{MHz}$.

Conversely, small values of $\eta_{t o t}$ lead to thermal contraction and a reduction of between $30 \mathrm{~km}$ in hmF2. The reduction in the strength of the equatorward wind around local midnight has little effect on the diurnal amplitude of hmF2.

The increase in the magnitude of $f_{\mathrm{oF}} 2$ is a direct result of the decrease in $N_{2}$ concentration in the thermosphere. A maximum value of $12.5 \mathrm{MHz}$ occurs at $0300 \mathrm{~h} \mathrm{LT}$.

\section{Sensitivity to the dissociation rate, $\mathbf{J}_{O_{2}}$}

We have shown that a diurnally-varying photodissociation rate plays a crucial role in the physics of the upper atmosphere over Argentine Islands. It is necessary to study the sensitivity of the upper atmosphere to varying levels of photodissociation.

As previously stated, we use $\mathrm{J}_{\mathrm{O}_{2}} \times 2$ as the upper limit and $\mathrm{J}_{\mathrm{O}_{2}} \times 0.5$ as the lower limit. The results from these two model runs can be seen in Figs. 10 and 11. The
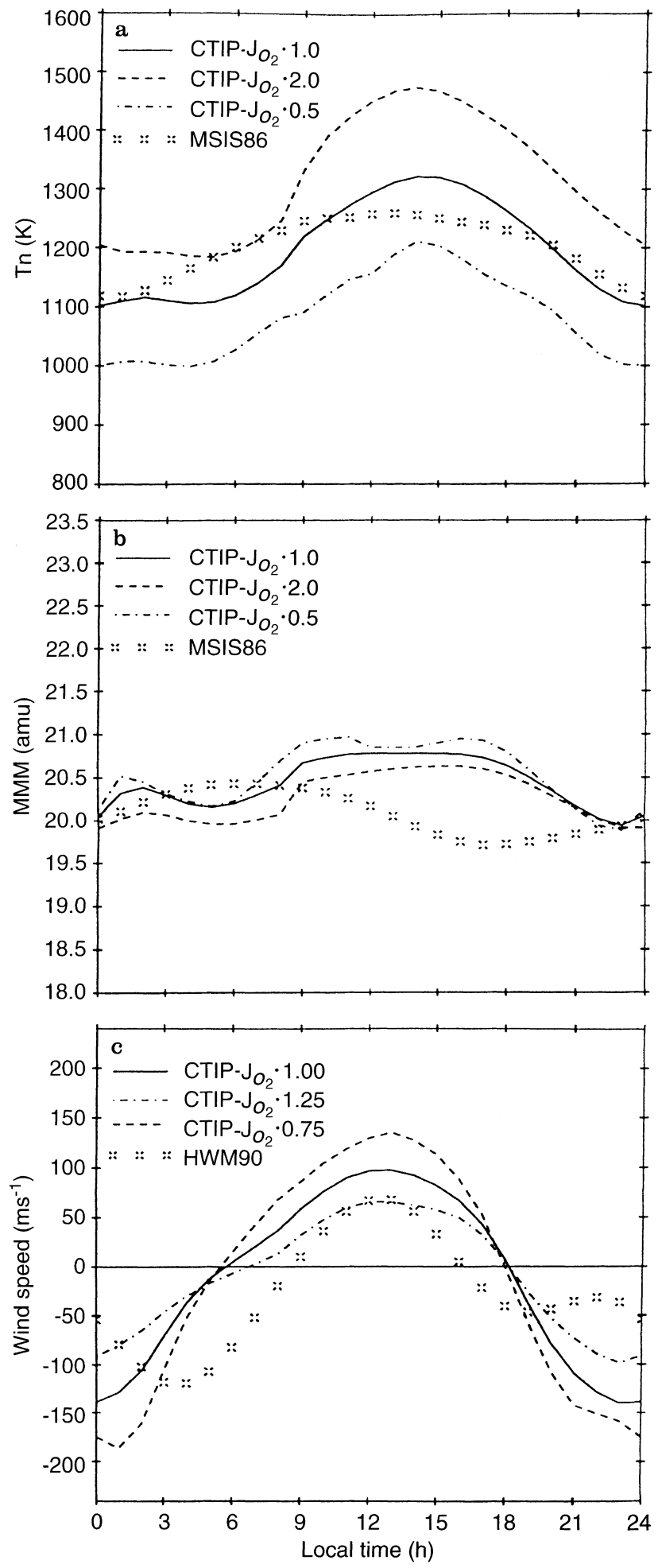

Fig. 10a-c. The sensitivity of a $T_{n} ; \mathbf{b} \mathrm{mmm}$ and $\mathbf{c} V_{x}$ (positive polewards), at $300 \mathrm{~km}$ over Argentine Islands, to changes in the magnitude of the $\mathrm{O}_{2}$ photodissociation rate 

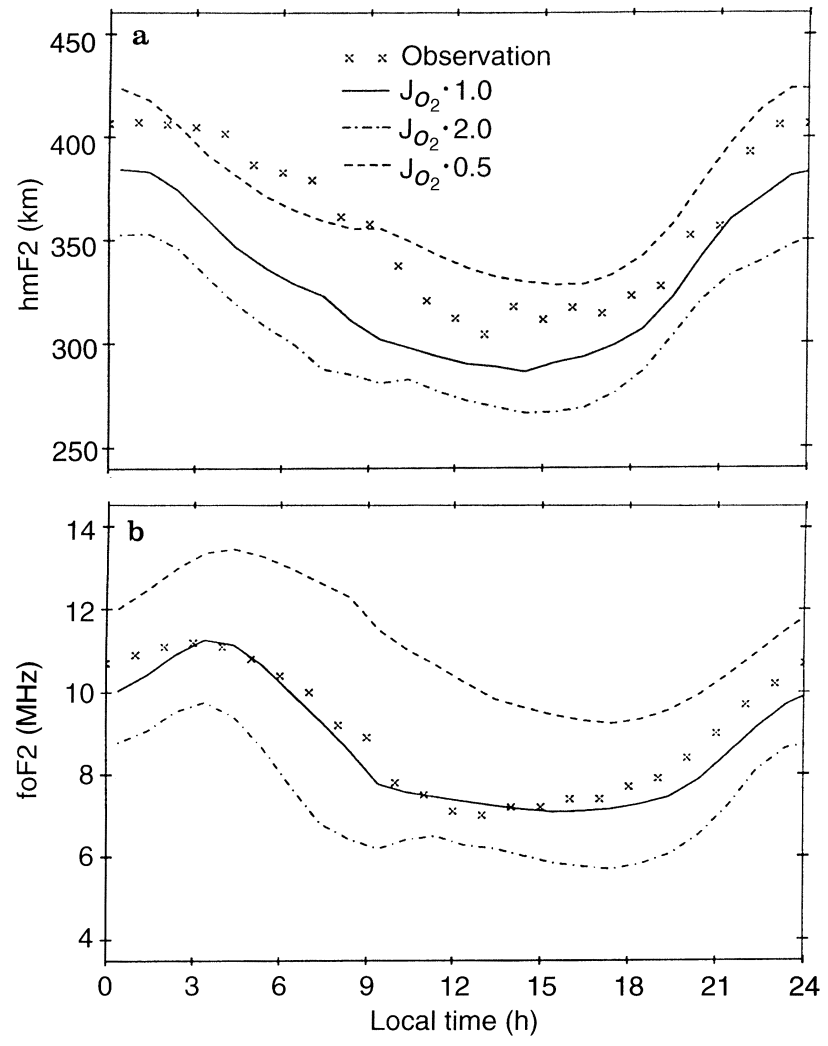

Fig. 11a,b. The sensitivity of a $\mathrm{hmF} 2$ and $\mathbf{b} f \mathrm{oF} 2$, over Argentine Islands, to changes in the magnitude of the $\mathrm{O}_{2}$ photodissociation rate

two primary consequences of the dissociation of molecular oxygen are neutral heating and production of atomic oxygen. Figure 10a shows that doubling $\mathrm{J}_{O_{2}}$ gives an increase of about $100 \mathrm{~K}$ in the diurnal amplitude of neutral temperature at $300 \mathrm{~km}$, with the largest effect at $1500 \mathrm{~h} \mathrm{LT}$. The temperature has increased by between $50-150 \mathrm{~K}$. However, halving $\mathrm{J}_{O_{2}}$ reduces $T_{n}$ by approximately $100 \mathrm{~K}$ throughout the day. The consequence of doubling and halving $\mathrm{J}_{\mathrm{O}_{2}}$ on the $\mathrm{mmm}$ is a decrease of about $0.5 \mathrm{amu}$ and a minimal increase, respectively (see Fig. 10b).

The effect of a change in $\mathrm{J}_{O_{2}}$ on the strength of $V_{x}$ can be seen in Fig. 10c. The larger rate produces an increase of about $25 \mathrm{~ms}^{-1}$ equatorwards at local midnight. Between 0600-1800 h LT, when the wind blows poleward, the wind strength is unaffected by the change. The smallest values of $\mathrm{J}_{O_{2}}$ cause an overall reduction of $V_{x}$. The maximum equatorward component of $V_{x}$ is reduced to $90 \mathrm{~ms}^{-1}$.

The effect of varying the dissociation rate on $\mathrm{hmF} 2$ and $f$ oF2 is shown in Fig. 11a,b. The doubling of $\mathbf{J}_{O_{2}}$ raises the height of the F2-layer by about $30 \mathrm{~km}$ throughout the day; halving $\mathrm{J}_{\mathrm{O}_{2}}$ causes $\mathrm{hmF} 2$ to fall by $20 \mathrm{~km}$ throughout the day.

The valves of $f_{\mathrm{oF}} 2$ resulting from doubling and halving the photodissociation rate are parallel to observations, but are displaced by $+2 \mathrm{MHz}$ and -1 $\mathrm{MHz}$ respectively.

\section{Conclusions}

This work is a new development in the evolution of CTIP. The introduction of $5.3 \mu \mathrm{m}$ NO cooling in the summer hemisphere, coupled with an improved description of the heating of the thermosphere by solar EUV and UV radiation and a diurnally varying dissociation rate, has had a significant effect on the thermosphere/ ionosphere system over Argentine Islands. Together, the changes that have been made provide a more complete description of the physics of the upper atmosphere over Argentine Islands during December solstice.

1. Our heating rates are larger throughout the day than those calculated by Creekmore et al. (1972) in the region 100-350 km over Argentine Islands during December solstice. The resulting higher neutral temperatures lead to an increase in the concentration of molecular species in the thermosphere. The inclusion of a diurnally varying dissociation rate reduces concentrations of molecular species, whilst leaving the wind and temperature distributions unaffected. The resulting F2layer forms at a higher altitude, whilst $f \circ \mathrm{oF} 2$ remains approximately the same magnitude as the layer which was formed using the Creekmore et al. (1972) heating rates. However, the large values of $T_{n}$ and $\mathrm{mmm}$ indicate that the amount of energy available to the thermosphere as heat is somewhat overestimated.

2. The inclusion of $5.3 \mu \mathrm{m}$ NO cooling, as a part of the heating efficiency calculation, reduces the neutral temperature to a value in good agreement with MSIS 86. The lower values of $T_{n}$ result in a thermosphere with a mean molecular mass that is also in better agreement with MSIS 86. This indicates that the overestimation of the thermospheric heating rate in summer could have been caused by the neglect of the heat loss due to $5.3 \mu \mathrm{m}$ NO. In terms of the F2-peak, NO cooling is seen to boost both the magnitude and diurnal amplitude of $f_{\mathrm{OF}} 2$ to a level comparable to observation. The thermal contraction of the atmosphere, caused by a drop in $T_{n}$, results in hmF2 being about $20 \mathrm{~km}$ lower than the values derived from observation. However, as described earlier, the scale of the errors involved in both CTIP and the derived values allows us to conclude that model results within $20 \mathrm{~km}$ of the derived values are in good agreement. Between 0300-1000 h LT the difference between the two curves reaches $50 \mathrm{~km}$.

3. The upper atmosphere has been shown to be sensitive to changes in the magnitude of heating efficiency. A change of $\pm 25 \%$ in the magnitude of heating efficiency results in a $\pm 10 \%$ change in $T_{n}$. Similarly, the magnitude of the $\mathrm{mmm}$ varies almost linearly with the magnitude of heating efficiency. An increase of $25 \%$ produces a decrease of 2 amu in $\mathrm{mmm}$ throughout the day. A decrease of $25 \%$ results in a rise of $2 \mathrm{amu}$ throughout the day. Consequently, the ionospheric parameters $f_{\mathrm{oF}} 2$ and $\mathrm{hmF} 2$ are sensitive to changes in heating efficiency. A higher temperature leads to a value of hmF2 in good agreement with the values derived from observation. However, $f \mathrm{oF} 2$ drops to a value unacceptably lower than observation. The converse is true in the case of the lower temperatures. 
4. It has been shown that the increase in the atomic oxygen concentration of the thermosphere is the major consequence of an increase in $\mathrm{J}_{O_{2}}$. The tendency of the $\mathrm{O} / \mathrm{N}_{2}$ ratio to decrease as a result of the larger neutral temperatures has been shown to be secondary to the additional atomic oxygen that is produced. The result of such an increase in $\mathbf{J}_{\mathrm{O}_{2}}$ is to force an increase in both $\mathrm{hmF} 2$, as the atmosphere expands, and $f \mathrm{oF} 2$, as the $\mathrm{O} / \mathrm{N}_{2}$ ration at the $\mathrm{F} 2$-peak is increased.

Fine tuning of the cooling and heating parameters might improve agreement between the model and observation. However, this is not considered worthwhile due to the considerable uncertainty in the values of the input parameters. The next step will be to extend the model/observation comparisons using other locations and atmospheric conditions.

Acknowledgements. G. D. Wells was supported by a Particle Physics and Astronomy Research Council (PPARC) studentship with a CASE award from British Antarctic Survey.

Topical Editor D. Alcaydé thanks R.W. Smith and M. Buonsanto for their help in evaluating this paper.

\section{References}

Brinkman, R. T., A. E. S. Green, and C. A. Barth, Tech. Rep. 32 951, Jet Propulsion Lab., California Inst. Tech., 1966.

Burns, A. G., T. L. Killeen, and R. G. Roble, Processes responsible for the compositional structure of the thermosphere, $J$. Geophys. Res., 94, 3670, 1989.

Chandra, S., and A. K. Sinha, The diurnal heat budget of the thermosphere, Planet. Space Sci., 21, 593, 1973.

Creekmore, S. P., E. L. Breig, B. K. Ching, and Y. T. Chiu, Tech. Rep. TR-0172(2260-20)-13, The Aerospace Corporation, 1972.

Dudeney, J. R., The accuracy of simple methods for determining the height of the maximum electron concentration of the F2layer from scaled ionospheric characteristics, J. Atmos. Terr. Phys., 45, 629, 1983.

Dudeney, J. R., and W. R. Piggott, Upper atmosphere research in Antarctica. Antarctic Res. Ser., 29, Paper 8, 1978.

Fuller-Rowell, T. J., and D. Rees, A three-dimensional timedependent global model of the thermosphere, J. Atmos. Sci., 37, 2194, 1980.
Fuller-Rowell, T. J., D. Rees, S. Quegan, R. J. Moffett, and G. J. Bailey, Interactions between neutral thermospheric composition and the polar ionosphere using a coupled ionosphere-thermosphere model, J. Geophys. Res., 92, 7744, 1987.

Fuller-Rowell, T. J., D. Rees, R. J. Moffett, S. Quegan, M. V. Codrescu, and G. H. Millward, A coupled thermosphereionosphere model, CTIM, in Aeronomical models of the ionosphere, STEP handbook (Ed. R.W. Schunk), 217, 1996.

Hedin, A. E., MSIS-86 thermospheric model, J. Geophys. Res., 92, 4649, 1987.

Hedin, A. E., M. A. Biondi, R. G. Burnside, G. Hernandez, R. M. Johnson, T. L. Killeen, C. Mazaudier, J. W. Meriwether, J. E. Salah, R. J. Sica, R. W. Smith, N. W. Spencer, V. B. Wickwar, and T. S. Virdi, Revised global model of thermospheric winds using satellite and ground based observation, J. Geophys. Res., 96, 7657, 1991

Heroux, L., and H. E. Hinteregger, Aeronomical reference spectrum for solar UV below 2000A, J. Geophys. Res., 83, $5305,1978$.

Hinteregger, H. E., The extreme ultraviolet solar spectrum and its variation during a solar cycle, Ann. Geophysique, 26, 547, 1970.

Millward, G. H., R. J. Moffett, S. Quegan, and T. J. Fuller-Rowell, A coupled thermosphere-ionosphere-plasmasphere model, CTIP, in Aeronomical models of the ionosphere, STEP handbook (Ed, R.W. Schunk), 239, 1996.

Quegan, S., G. J. Bailey, R. J. Moffett, R. A. Heelis, T. J. FullerRowell, D. Rees and R. W. Spiro, A theoretical study of the distribution of ionisation in the high-latitude ionosphere and the plasmasphere: first results on the mid-latitude trough and the light ion trough, J. Atmos. Terr. Phys., 44, 619, 1982.

Richards, P. G., M. R. Torr, and D. G. Torr, The seasonal effect of nitric oxide cooling on the thermospheric U.V. heat budget, Planet. Space Sci., 30, 515, 1982.

Stolarski, R. S., P. B. Hays, and R. G. Roble, Atmospheric heating by solar EUV radiation, J. Geophys. Res., 80, 2266, 1975.

Tobiska, W. K., Revised solar extreme ultraviolet flux model, $J$. Atmos. Terr. Phys., 53, 1005, 1991.

Torr, M. R., and D. G. Torr, The role of metastable species in the thermosphere, Rev. Geophys. Space Phys., 20, 91, 1982.

Torr, M. R., D. G. Torr, and P. G. Richards, The solar ultraviolet heating efficiency of the midlatitude thermosphere, Geophys. Res. Lett., 7, 373, 1980a.

Torr, M. R., P. G. Richards, and D. G. Torr, A new determination of the ultraviolet heating efficiency of the thermosphere, $J$. Geophys. Res., 85, 6189, 1980b.

Watanabe, K., Ultraviolet absorption processes in the upper atmosphere., Adv. Geophys. 5, 153, 1958. 